\title{
Polonium-210: its relative enrichment in the hepatopancreas of marine invertebrates
}

\author{
R. D. Cherry ${ }^{1 *}$, M. Heyraud ${ }^{1}$ and J. J. W. Higgo ${ }^{2 * *}$ \\ ${ }^{1}$ International Laboratory of Marine Radioactivity, Musée Océanographique, Monaco \\ ${ }^{2}$ Physics Department, University of Cape Town, Rondebosch, C. P., 7700 , South Africa
}

\begin{abstract}
Po}$ is known to be enriched in many components of the marine biosphere. Particularly high concentrations of ${ }^{210}$ Po are found in the hepatopancreas of many marine invertebrates, making this organ one of the highest known natural radiation dose domains. Concentrations of many other elements in the hepatopancreas have been reported in the literature, and these are summarised and compared with those for ${ }^{210} \mathrm{Po}$. The enrichment factor concept is used, and a simple marine biogeochemical classification of the elements results. The enrichment factors for Ag, Cd and $\mathrm{Se}$ in the marine hepatopancreas are found to be even higher than that for ${ }^{210} \mathrm{Po}$; those for $\mathrm{Cu}, \mathrm{Hg}$. $\mathrm{Sb}$ and $\mathrm{Zn}$ are an order of magnitude lower, and those for all other elements for which data are available are at least one order of magnitude lower still. The idea that ${ }^{210} \mathrm{Po}$ is closely involved with biological processes in the ocean is given additional support.
\end{abstract}

\section{INTRODUCTION}

The marine geochemistry of the naturally-occurring alpha-radioactive nuclide ${ }^{210} \mathrm{Po}$ exhibits unusual and interesting features, as is seen most strikingly if one compares the levels of ${ }^{210} \mathrm{Po}$ with those of its grandparent ${ }^{210} \mathrm{~Pb}$. The ${ }^{210} \mathrm{~Pb} / 210 \mathrm{~Pb}$ activity ratio is about $0.1 \mathrm{in}$ the atmospheric particles which fall into the ocean, 0.5 in sea water, 2 in zooplankton faecal pellets, 20 in whole zooplankton and 100 in the hepatopancreas of many marine invertebrates (Cherry and Shannon, 1974; Cherry and Heyraud, 1982). The high ratios in the biological materials reflect high ${ }^{210} \mathrm{Po}$ rather than low ${ }^{210} \mathrm{~Pb}$ concentrations, and this enrichment of ${ }^{210} \mathrm{Po}$ in marine organisms has important implications in the radiobiological as well as in the biogeochemical field. Radiobiologically, ${ }^{210} \mathrm{Po}$ provides the major contribution to the natural radiation dose received by most marine organisms (Cherry and Shannon, 1974). In the hepatopancreas of marine invertebrates the radiation dose from ${ }^{210}$ Po ranges from 1300 to 280000 mrem yr $^{-1}$ (Heyraud and Cherry, 1979; Cherry and Heyraud. 1981, 1982); in comparison, the human organ which

\footnotetext{
- On leave from Physics Department, University of Cape Town, Rondebosch, C. P., 7700, South Africa

- Cument address: Chemistry Department, Imperial College of Science and Technology, London SW7 2 AY, England
}

receives the highest natural radiation dose is the lung, with a typical dose from all sources of about $400 \mathrm{mrem}$ $\mathrm{yr}^{-1}$ (UNSCEAR, 1977). The hepatopancreas of marine invertebrates, together with the pyloric caecum of fish (Folsom et al., 1972; Heyraud and Cherry, 1979; Cherry and Heyraud, 1982) appears to constitute the highest known natural radiation dose domain in our biosphere. As such, it is clearly worthy of detailed investigation, and the mechanism of ${ }^{210}$ Po enrichment in this organ needs to be studied.

Why is ${ }^{210} \mathrm{Po}$ enriched in marine biological materials, and how does its degree of enrichment compare with that of other elements? It should be emphasized that, although ${ }^{210}$ Po activities in question are high in comparison with the levels of natural radioactivity normally encountered in biological samples, the atom concentrations are very low indeed: even a fairly high ${ }^{210} \mathrm{Po}$ activity of $100 \mathrm{dpm} \mathrm{g}^{-1}$ wet tissue corresponds to only 1 part in $10^{14}$ by mass. It seems inconceivable that ${ }^{210}$ Po could be a biologically essential trace element. Almost nothing is known about the chemical speciation of ${ }^{210} \mathrm{Po}$ in the marine environment, and information on this subject will be difficult to obtain in view of the very small atom concentrations involved. At this stage, a synthesis of the available data seems to be indicated. Many elements are, for example, known to be enriched in the hepatopancreas, yet to our know- 
ledge no attempt has been made to collate the published data and to classify the elements which have been measured (all metals or metalloids) according to the degree of enrichment involved. We do so here, using the well-known geochemical concept of enrichment factors. We compare these factors in the hepatopancreas with those in other components of the marine environment, and find ${ }^{210} \mathrm{Po}$ in the company of elements which appear to be associated with biological cycles in the ocean. The resulting classification is used to draw attention to element associations which might help us understand the mechanisms influencing ${ }^{210}$ Po uptake in the hepatopancreas.

\section{DATA SUMMARY}

Element concentrations in the hepatopancreas of marine invertebrates are summarized in Table 1. The data on which they are based cover hepatopancreas from molluscs (gastropods, lamellibranchs and cephalopods) and from crustaceans. The data for ${ }^{210} \mathrm{Po}$ are particularly extensive, and cover more than 30 different species (Cherry and Shannon, 1974; Heyraud and Cherry, 1979; Cherry and Heyraud, 1981; Cherry and Heyraud, 1982); those for ${ }^{210} \mathrm{~Pb}$ are also extensive, although of poorer quality; those for other heavy radionuclides are very limited although a recent publication (Guary et al., 1981) has rectified this situation with data for ${ }^{241} \mathrm{Am},{ }^{239+240} \mathrm{Pu}$ and ${ }^{232} \mathrm{Th}$. A gap remains, viz. for ${ }^{210} \mathrm{Bi}$, the daughter of ${ }^{210} \mathrm{~Pb}$ and the immediate parent of ${ }^{210} \mathrm{Po}$. We were unable to find any ${ }^{210} \mathrm{Bi}$ data in the literature, and we thought it important to measure ${ }^{210} \mathrm{Bi}$ in the hepatopancreas of at least a few species.

Our results show ${ }^{210} \mathrm{Bi}$ at levels which are at the same order of magnitude as those for ${ }^{210} \mathrm{~Pb}$, or 2 orders of magnitude below those for ${ }^{210} \mathrm{Po}$. Clearly, the high ${ }^{210}$ Po observed in the hepatopancreas is not due simply to ${ }^{210} \mathrm{Bi}$ uptake, but must reflect direct uptake of ${ }^{210} \mathrm{Po}$ itself. Insofar as the stable elements are concerned, our literature search was assisted greatly by Eisler's book (Eisler, 1981) and by the annotated bibliographies of Eisler and his collaborators (Eisler, 1973; Eisler and Wapner, 1975; Eisler et al., 1978, 1979); we believe it to be thorough although we do not claim it to be exhaustive. Certain of the early values tended to be high in comparison with the vast body of more recent data, and we decided to exclude pre-1950 determinations. We believe this decision to be justified in view of the more sophisticated techniques for trace element analysis which have come into use in recent years. Data from estuarine locations and from areas designated as contaminated' were also excluded. We mention too that
Table 1. Element concentrations in the hepatopancreas of marine invertebrates. Values are $\mu \mathrm{g} \mathrm{g}^{-1}$ dry except for ${ }^{241} \mathrm{Am}$, ${ }^{210} \mathrm{Bi},{ }^{210} \mathrm{Po},{ }^{210} \mathrm{~Pb}$ and ${ }^{239} \mathrm{Pu}$ which are in $\mathrm{dpm} \mathrm{g}^{-1} \mathrm{dry}$. Concentration factor from sea water to wet hepatopancreas assuming a wet/dry ratio of 3 for the organ. Sea water data from Brewer (1975) except for ${ }^{210} \mathrm{Po},{ }^{210} \mathrm{~Pb}$ and Th which were from Cherry and Shannon (1974) and ${ }^{241} \mathrm{Am}$ and ${ }^{239} \mathrm{Pu}$ which are from Fukai et al. (1976). For reasons of space, the original references for the hepatopancreas data are not cited; most of them are to be found in the compilations of Eisler and his colleagues referred to in the text. Hitherto unpublished hepatopancreas data are those of Cherry and Heyraud for ${ }^{210} \mathrm{Bi}$; determination of ${ }^{210} \mathrm{Bi}$ was by the method of Mackenzie and Scott (1979), in the hepatopancreas of the molluscan cephalopod Eledone aldrovandii and the crustacean shrimp Parapenaeus keraturus. ${ }^{239} \mathrm{Pu}$ is strictly ${ }^{239+240} \mathrm{Pu}$ ' whenever it occurs

\begin{tabular}{|c|c|c|c|}
\hline Element & $\begin{array}{l}\text { Range } \\
\text { of values }\end{array}$ & $\begin{array}{l}\text { Typical } \\
\text { value }\end{array}$ & $\begin{array}{c}\text { Concentration } \\
\text { factor }\end{array}$ \\
\hline $\mathrm{Ag}$ & $0.3-\quad 96$ & 10 & $1 \times 10^{5}$ \\
\hline Al & $40-\quad 860$ & 100 & $2 \times 10^{4}$ \\
\hline${ }^{241} \mathrm{Am}$ & 0.0002 & 0.0002 & $5 \times 10^{2}$ \\
\hline As & $68-\quad 210$ & 100 & $9 \times 10^{3}$ \\
\hline${ }^{210} \mathrm{Bi}$ & $0.7-\quad 2.0$ & 1 & $3 \times 10^{3}$ \\
\hline $\mathrm{Ca}$ & $400-9,000$ & 1,000 & $1 \times 10^{0}$ \\
\hline $\mathrm{Cd}$ & $2.2-1,200$ & 50 & $2 \times 10^{5}$ \\
\hline $\mathrm{Co}$ & $0.36-\quad 61$ & 2 & $1 \times 10^{4}$ \\
\hline $\mathrm{Cr}$ & $0.19-\quad 150$ & 8 & $9 \times 10^{3}$ \\
\hline $\mathrm{Cu}$ & $7-14,000$ & 300 & $2 \times 10^{5}$ \\
\hline$E_{U I}$ & $0.012-0.017$ & 0.01 & $3 \times 10^{2}$ \\
\hline $\mathrm{Fe}$ & $19-4,900$ & 400 & $7 \times 10^{4}$ \\
\hline $\mathrm{Ga}$ & $0.014-\quad 0.79$ & 0.1 & $1 \times 10^{3}$ \\
\hline $\mathrm{Hg}$ & $0.06-\quad 7.6$ & 0.3 & $3 \times 10^{3}$ \\
\hline $\mathrm{K}$ & $3,700-4,400$ & 4,000 & $4 \times 10^{0}$ \\
\hline $\mathrm{Mg}$ & $2,000-14,000$ & 5,000 & $1 \times 10^{\circ}$ \\
\hline $\mathrm{Mn}$ & $4-\quad 410$ & 20 & $3 \times 10^{4}$ \\
\hline $\mathrm{Na}$ & $26,000-39,000$ & 30,000 & $1 \times 10^{\circ}$ \\
\hline $\mathrm{Ni}$ & $0.59-\quad 170$ & 3 & $6 \times 10^{2}$ \\
\hline $\mathrm{Pb}$ & $0.6-\quad 40$ & 4 & $4 \times 10^{4}$ \\
\hline${ }^{210} \mathrm{~Pb}$ & $0.07-\quad 4.4$ & 1 & $3 \times 10^{3}$ \\
\hline${ }^{210} \mathrm{Po}$ & $8-1,900$ & 100 & $6 \times 10^{5}$ \\
\hline${ }^{239} \mathrm{Pu}$ & 0.005 & 0.005 & $7 \times 10^{2}$ \\
\hline $\mathrm{Sb}$ & 0.6 & 0.6 & $8 \times 10^{2}$ \\
\hline Se & $7-$ & 9 & $2 \times 10^{4}$ \\
\hline $\mathrm{Sn}$ & $0.4-$ & 1 & $3 \times 10^{4}$ \\
\hline $\mathrm{Sr}$ & 5- & 10 & $4 \times 10^{-1}$ \\
\hline Th & 0.02 & 0.02 & $7 \times 10^{3}$ \\
\hline $\mathrm{U}$ & $0.28-\quad 0.83$ & 0.4 & $4 \times 10^{1}$ \\
\hline $\mathrm{Zn}$ & $46-8,000$ & 300 & $2 \times 10^{4}$ \\
\hline
\end{tabular}

the hepatopancreas is variously named in the literature: frequently it is referred to as 'digestive gland', sometimes as 'mid-gut gland' and occasionally (erroneously) as 'liver'. Where data were cited on a wet-weight basis only, a wet/dry ratio of 3.0 was assumed for hepatopancreas tissue (Heyraud and Cherry, 1979).

We quote the range of values observed for each element and also a 'typical' value. The latter is of course subjective, and we would not care to have to justify our choices to better than a factor of about 3 . The 
widest range of values (over 3 orders of magnitude) is for $\mathrm{Cu}$. For this element there is a clear tendency for the levels in hepatopancreas from the cephalopods to be at the upper end of the range; possibly this reflects the fact that the blood of cephalopods contains higher concentrations of haemocyanin, a copper-containing protein, than does that of other molluscs or of crustaceans (Prosser and Brown, 1962). Our 'typical' value for $\mathrm{Cu}$ must be regarded as a rather unsatisfactory compromise which covers 2 or more different populations. Such a multi-population situation arises also for Fe and $\mathrm{Mn}_{\text {; }}$ in these cases it is levels in the lamellibranchs which are generally elevated while those in the cephalopods and the crustaceans are depressed. For the other elements no unambiguous differences between animal classes and phyla are observed, and large ranges are often found on examination to be exaggerated by a few extreme values. For ${ }^{210} \mathrm{Po}_{\text {, the }}$ large range found is real, and the variations have, in crustacean Decapoda, been correlated with biological and environmental factors (Cherry and Heyraud, 1981). For no element is there any difficulty in assigning the order of magnitude to the typical value, and we are confident that there will be little disagreement with our assessment of the data to this degree of accuracy.

Also included in Table 1 are the concentration factors from sea water to the hepatopancreas. We see immediately that the factor for ${ }^{210} \mathrm{Po}$ is the highest of all elements for which data are available but that it is followed closely by $\mathrm{Cd}, \mathrm{Cu}$ and $\mathrm{Ag}$. These concentration factors do, however, depend on the sea water data, and are unsatisfactory in some respects, e. g. it is not clear whether or not the particulate contribution should be included in the sea water data; further, many of the organisms for which hepatopancreas data are available are from coastal environments, whereas the sea water data are largely oceanic.

\section{ENRICHMENT FACTOR CLASSIFICATION OF ELEMENTS}

It is in many ways more profitable to compare the hepatopancreas data with those from oceanographic domains other than sea water; it is also more useful and more significant to depart from the idea of a simple concentration factor and to use instead the concept of an enrichment factor which has been employed so fruitfully by workers concerned with trace elements in atmospheric and oceanic particulates (Zoller et al., 1974; Duce et al., 1975; Buat-Menard and Chesselet, 1979). This concept uses $\mathrm{Al}$ as the reference element and the earth's crust as the reference material; the enrichment factor EF can then be defined as follows for any element $X$ in any sample material:

$$
E F=\frac{(X / A l) \text { sample }}{(X / A l) \text { crust }}
$$

For $\mathrm{Al}$, the $\mathrm{EF}$ is by definition unity in all samples. The aluminium content of biogenous matter is usually low (Bennett and Carpenter, 1979) and elements which are involved in the biological cycle will have EF values which are greater than one: thus carbon in typical dry biological material, to quote an extreme example, will have EF between $10^{6}$ and $10^{7}$.

The results of these enrichment factor calculations are given in Table 2, from which ${ }^{241} \mathrm{Am}, \mathrm{As},{ }^{210} \mathrm{Bi}$, Ga and $\mathrm{Sn}$ have been omitted because of lack of data for these elements in most domains. The element Sc has, on the other hand, been added. All calculations have used the average crustal abundances of Taylor (1964). In addition to the marine hepatopancreas we have chosen different 'sample' materials reflecting various stages in the oceanographic elemental cycle and various degrees of involvement in biological processes. Data for these various materials have been taken from the sources indicated in the table. Once again a certain amount of subjectivity is involved in the choice of 'typical' values, but, as for the hepatopancreas, no substantial controversy is likely insofar as the orders of magnitude are concerned. Only for the zooplankton faecal pellets do we feel that it is necessary to cite the original data, because we have added to the sparse published data a few unpublished values of our own: the situation is summarized in Tables 3 and 4 . The 'green' faecal pellets as found in the Spencer et al. (1978) sediment trap are not strictly equivalent to the freshly produced faecal pellets of the euphausiids Meganyctiphanes norvegica, but they are probably sufficiently similar for purposes of the present argument.

The elements and the columns in Table 2 are ordered in such a way as to show conveniently and systematically the trends in enrichment factor as one moves from left to right and from top to bottom. An alternative presentation would have been to order the columns so as to reflect a possible sequence of exchanges from one reservoir to the next, e.g. atmospheric particulates $\rightarrow$ zooplankton $\rightarrow$ hepatopancreas$\rightarrow$ faecal pellets $\rightarrow$ sediment trap. We have preferred our ordering not only because it shows the increasing or decreasing trends in EF more neatly, but also because our primary aim in this table is to highlight the situation in the hepatopancreas.

The elements can be divided into 4 obvious biogeochemical groups, as indicated by the horizontal lines. In the first group we have the elements $\mathrm{Sc}_{\text {, }} \mathrm{Th}$ and $\mathrm{Eu}$, for which the enrichment factors are not far 
Table 2. Enrichment factors (EF) for elements in oceanic materials. The following data sources and typical Al values were used in calculating the EF. Mid-water ocean sediment trap (Brewer et al., 1980; 3,755 and 3,694 m depth traps; typical Al at 25,800 $\mu \mathrm{g} \mathrm{\textrm {g } ^ { - 1 }}$ dry); zooplankton faecal pellets (Tables 3 and 4, this paper); atmospheric particulates (Zoller et al., 1974; Duce et al., 1975; Wallace et al., 1977; Buat-Menard and Chesselet, 1979; EF are given in these references, so a typical Al value was not needed; ${ }^{210} \mathrm{~Pb}$ and ${ }^{239} \mathrm{Pu}$ from Scripps Pier filter samples of Hodge et al., 1978); ${ }^{210} \mathrm{Po} /{ }^{210} \mathrm{~Pb}$ activity ratio of 0.1 assumed for atmospheric particulates (Lambert et al., 1979); zooplankton (Martin, 1970; Martin and Knauer, 1973; Cherry and Shannon, 1974; Fowler, 1977; Higgo et al., 1980; typical Al at $100 \mu \mathrm{g} \mathrm{g} \mathrm{g}^{-1}$ dry); marine hepatopancreas (Table 1, this paper). Crustal abundance from Taylor (1964); $\mathrm{Al}$ at $82,300 \mathrm{~g} \mathrm{~g}^{-1}$; crustal abundances for ${ }^{210} \mathrm{Po}$ and ${ }^{210} \mathrm{~Pb}$ assume radioactive equilibrium with ${ }^{238} \mathrm{U}$; $\mathrm{crustal}$ abundances for ${ }^{241} \mathrm{Am}$ and ${ }^{239} \mathrm{Pu}$ are not available, and the surface soil data of Thein et al. (1980) have been used as an approximation

\begin{tabular}{|c|c|c|c|c|c|}
\hline & $\begin{array}{l}\text { Mid-water } \\
\text { sediment trap }\end{array}$ & $\begin{array}{l}\text { Zooplankton } \\
\text { faecal pellets }\end{array}$ & $\begin{array}{l}\text { Atmospheric } \\
\text { particulates }\end{array}$ & Zooplankton & $\begin{array}{c}\text { Marine } \\
\text { hepatopancreas }\end{array}$ \\
\hline $\mathrm{Sc}$ & $5 \times 10^{-1}$ & $6 \times 10^{-1}$ & $8 \times 10^{-1}$ & $2 \times 10^{0}$ & - \\
\hline $\mathrm{Th}$ & $1 \times 10^{0}$ & $9 \times 10^{-1}$ & $2 \times 10^{0}$ & $4 \times 10^{0}$ & $2 \times 10^{0}$ \\
\hline $\mathrm{Eu}$ & - & $2 \times 10^{0}$ & - & $3 \times 10^{0}$ & $7 \times 10^{0}$ \\
\hline $\mathrm{Fe}$ & $6 \times 10^{-1}$ & $2 \times 10^{0}$ & $2 \times 10^{0}$ & $6 \times 10^{0}$ & $6 \times 10^{0}$ \\
\hline $\mathrm{Mn}$ & $2 \times 10^{0}$ & $9 \times 10^{-1}$ & $2 \times 10^{0}$ & $7 \times 10^{0}$ & $2 \times 10^{1}$ \\
\hline $\mathrm{Ni}$ & - & $2 \times 10^{0}$ & $4 \times 10^{0}$ & $7 \times 10^{1}$ & $3 \times 10^{1}$ \\
\hline $\mathrm{Co}$ & $1 \times 10^{0}$ & $2 \times 10^{0}$ & $2 \times 10^{0}$ & $2 \times 10^{1}$ & $7 \times 10^{1}$ \\
\hline $\mathrm{Cr}$ & - & $2 \times 10^{\circ}$ & $7 \times 10^{0}$ & $2 \times 10^{1}$ & $7 \times 10^{1}$ \\
\hline $\mathrm{Ca}$ & $2 \times 10^{0}$ & $1 \times 10^{1}$ & $2 \times 10^{0}$ & $4 \times 10^{2}$ & $2 \times 10^{1}$ \\
\hline $\mathrm{Sr}$ & $1 \times 10^{1}$ & $1 \times 10^{1}$ & - & $2 \times 10^{3}$ & $2 \times 10^{1}$ \\
\hline $\mathrm{U}$ & $2 \times 10^{0}$ & $3 \times 10^{0}$ & - & $1 \times 10^{2}$ & $1 \times 10^{2}$ \\
\hline $\mathrm{K}$ & $7 \times 10^{-1}$ & $1 \times 10^{0}$ & $2 \times 10^{0}$ & $4 \times 10^{2}$ & $2 \times 10^{2}$ \\
\hline $\mathrm{Mg}$ & $1 \times 10^{0}$ & $2 \times 10^{0}$ & $7 \times 10^{0}$ & $4 \times 10^{2}$ & $2 \times 10^{2}$ \\
\hline $\mathrm{Na}$ & - & $3 \times 10^{0}$ & $5 \times 10^{1}$ & $3 \times 10^{3}$ & $1 \times 10^{3}$ \\
\hline $\mathrm{Pb}$ & - & $1 \times 10^{1}$ & $4 \times 10^{2}$ & $7 \times 10^{2}$ & $3 \times 10^{2}$ \\
\hline${ }^{210} \mathrm{~Pb}$ & $6 \times 10^{2}$ & $4 \times 10^{1}$ & $2 \times 10^{3}$ & $2 \times 10^{2}$ & $4 \times 10^{2}$ \\
\hline${ }^{239} \mathrm{Pu}$ & - & $6 \times 10^{1}$ & $2 \times 10^{2}$ & $4 \times 10^{3}$ & $8 \times 10^{2}$ \\
\hline $\mathrm{Sb}$ & $1 \times 10^{2}$ & $2 \times 10^{2}$ & $1 \times 10^{3}$ & $5 \times 10^{2}$ & $2 \times 10^{3}$ \\
\hline $\mathrm{Zn}$ & $2 \times 10^{1}$ & $6 \times 10^{1}$ & $8 \times 10^{1}$ & $2 \times 10^{3}$ & $3 \times 10^{3}$ \\
\hline $\mathrm{Hg}$ & - & $2 \times 10^{1}$ & $5 \times 10^{2}$ & $3 \times 10^{3}$ & $3 \times 10^{3}$ \\
\hline $\mathrm{Cu}$ & $1 \times 10^{1}$ & $2 \times 10^{1}$ & $8 \times 10^{1}$ & $4 \times 10^{2}$ & $4 \times 10^{3}$ \\
\hline${ }^{210} \mathrm{Po}$ & $1 \times 10^{3}$ & $8 \times 10^{1}$ & $2 \times 10^{2}$ & $4 \times 10^{3}$ & $4 \times 10^{4}$ \\
\hline $\mathrm{Ag}$ & - & $1 \times 10^{2}$ & $2 \times 10^{2}$ & $5 \times 10^{3}$ & $1 \times 10^{5}$ \\
\hline $\mathrm{Cd}$ & - & $2 \times 10^{2}$ & $7 \times 10^{2}$ & $1 \times 10^{4}$ & $2 \times 10^{5}$ \\
\hline $\mathrm{Se}$ & - & $6 \times 10^{2}$ & $1 \times 10^{4}$ & $4 \times 10^{4}$ & $2 \times 10^{5}$ \\
\hline
\end{tabular}

from $10^{\circ}$ for all types of sample material listed. Aluminium itself is, by definition, a member of this group. Such elements are packaged by zooplankton into faecal pellets, their rapid transfer to the deep ocean being thereby assisted, but they do not become enriched appreciably in marine biological processes. In the second group we have the transition metals with atomic numbers between 23 and 28. For these elements the EF in the sediment trap material are essentially unity, but as we move across the table to the right there is in general a tendency for the EF to increase gently until they exceed $10^{1}$ in zooplankton and in the hepatopancreas. Most of these elements have been associated by previous workers with particulate organic matter and biogenic debris and/or with the formation of a hydroxide phase (Buat-Menard and Chesselet, 1979). The third group contains the ele- ments with oceanic residence times longer than $10^{6} \mathrm{y}$ (Brewer, 1975). It is interesting to note that for them the tendency for EF to increase to the right does not persist to the last column; their EF are generally less in the hepatopancreas than in zooplankton. Finally, we come to the fourth, or bottom, group. It is here that we find ${ }^{210} \mathrm{Po}$ and ${ }^{210} \mathrm{~Pb}$ and with them are ${ }^{239} \mathrm{Pu}$ and stable $\mathrm{Pb}$. $\mathrm{Sb}, \mathrm{Zn}, \mathrm{Hg}, \mathrm{Cu}, \mathrm{Ag}, \mathrm{Cd}$ and Se. Most of these stable elements have been grouped together on previous occasions for diverse reasons and purposes: geochemically, they all belong to the chalcophile (tendency to be bound to sulphur) classification (Whitfield, 1979); they are all classified as 'very toxic and relatively accessible' (Wood, 1974); they rank high in their ease of release to the atmosphere and their ready availability for mobilization in the environment (Lantzy and MacKenzie, 1979; Bertine and Goldberg, 1971); they 
Table 3. Element concentrations ( $\mu \mathrm{g} \mathrm{g}^{-1}$ dry) in faecal pellets. GFPS, Green faecal pellets of Spencer et al., 1978; MNFPF, Meganyctiphanes norvegica faecal pellets of Fowler, 1977; MNFPH, $M$. norvegica faecal pellets; element determinations by atomic absorption spectroscopy (Higgo, unpubl.) except for Th and U (Higgo et al., 1980)

\begin{tabular}{|c|c|c|c|c|}
\hline Element & GFPS & MNFPF & MNFPH & $\begin{array}{c}\text { Typical } \\
\text { value }\end{array}$ \\
\hline $\mathrm{Ag}$ & - & 2.1 & - & 2 \\
\hline $\mathrm{Al}$ & 21,000 & - & 16,000 & 20,000 \\
\hline $\mathrm{Ca}$ & 232,000 & - & 49,000 & 100,000 \\
\hline $\mathrm{Cd}$ & - & 9.6 & - & 10 \\
\hline $\mathrm{Co}$ & 15 & 3.5 & - & 10 \\
\hline $\mathrm{Cr}$ & - & 38 & - & 40 \\
\hline $\mathrm{Cu}$ & 650 & 226 & 220 & 300 \\
\hline Eu & - & 0.66 & - & 0.7 \\
\hline $\mathrm{Fe}$ & 22,000 & 24,000 & 18,000 & 20,000 \\
\hline $\mathrm{Hg}$ & - & 0.34 & - & 0.3 \\
\hline $\mathrm{K}$ & - & - & 6,000 & 6,000 \\
\hline $\mathrm{Mg}$ & 8,000 & - & 16,000 & 10,000 \\
\hline Mn & 2,110 & 243 & 150 & 200 \\
\hline $\mathrm{Na}$ & - & - & 15,000 & 15,000 \\
\hline $\mathrm{Ni}$ & - & 20 & 40 & 30 \\
\hline $\mathrm{Pb}$ & - & 34 & - & 30 \\
\hline $\mathrm{Sb}$ & $<5$ & 71 & - & 10 \\
\hline $\mathrm{Sc}$ & 4 & 2.8 & - & 3 \\
\hline $\mathrm{Se}$ & - & 6.6 & - & 7 \\
\hline $\mathrm{Sr}$ & 1,430 & 78 & 1,250 & 1,000 \\
\hline Th & - & - & 2.3 & 2 \\
\hline$U$ & - & - & 1.6 & 2 \\
\hline $\mathrm{Zn}$ & $<20$ & 950 & 2,730 & 1,000 \\
\hline
\end{tabular}

Table 4. ${ }^{210} \mathrm{Po},{ }^{210} \mathrm{~Pb}$ and ${ }^{239} \mathrm{Pu}$ in freshly-collected faecal pellets. All values in $\mathrm{dpm} \mathrm{g}^{-1}$ dry. Meganyctiphanes norvegica data from Cherry et al. (1975); Higgo et al. (1977); Beasley et al. (1978); Higgo et al. (1980) and Heyraud (1982). Data for other zooplankton from Heyraud (1982) includes data for faecal pellets from copepods, salps and planktonic shrimp

\begin{tabular}{|cccc|}
\hline Element & $\begin{array}{c}\text { M.norvegica } \\
\text { faecal pellets }\end{array}$ & $\begin{array}{c}\text { Other } \\
\text { zooplankton } \\
\text { faecal pellets }\end{array}$ & $\begin{array}{c}\text { Typical } \\
\text { value }\end{array}$ \\
\hline${ }^{210} \mathrm{Po}$ & $24-62$ & $15-67$ & 40 \\
${ }^{210} \mathrm{~Pb}$ & $6-31$ & $4-20$ & 20 \\
${ }^{239} \mathrm{Pu}$ & $0.05-0.69$ & - & 0.15 \\
\hline
\end{tabular}

have high EF in particulates in the ocean itself (Wallace et al., 1977; Buat-Menard and Chesselet, 1979); they belong, as does ${ }^{210} \mathrm{Po}$ (Heyraud and Cherry, 1983), to a group of elements for which the possibility of a significant flux from the sea surface to the atmosphere has been suggested (Lantzy and MacKenzie, 1979).

From Table 2 we see that these elements are enriched even in sediment trap material and in faecal pellets which are, for the 3 previous groups of elements, rather close to crustal material in their relative composition. In atmospheric particulates and in zooplankton the EF rise to between $10^{1}$ and $10^{4}$ while in the hepatopancreas they are generally higher still, at between $10^{2}$ and $10^{5}$. The EF reaches its highest value in the hepatopancreas for 8 of the 10 elements listed, viz. for $\mathrm{Sb}, \mathrm{Zn}, \mathrm{Hg}, \mathrm{Cu},{ }^{210} \mathrm{Po}, \mathrm{Ag}, \mathrm{Cd}$ and $\mathrm{Se}$. For all the elements in the bottom group in Table 2 the words which Buat-Menard and Chesselet (1979) applied to a similar, although not identical, group of elements appear to be very pertinent: 'it is likely that, for these elements, the enrichment in the ocean is due to processes within the marine regime, for example their involvement in the biological cycle of the ocean.'

Since our prime interest is the problem of ${ }^{210} \mathrm{Po}$ in the marine hepatopancreas, it is worth looking at this group of 'biologically involved' elements in more detail. Two caveats must be borne in mind. Firstly, the EF figures cited cannot be given credence to more than a factor of 3 or so; for the sediment trap material and faecal pellets the situation is even worse because of the paucity of data. Secondly, it should be emphasized that the grouping together of these elements in no way implies complete uniformity in their chemical behaviour. Wide variations are to be expected, and are indeed observed, and these reflect the different chemical processes which operate for different elements. For example, a glance at Table 2 shows a striking difference between ${ }^{210} \mathrm{Po}$ and ${ }^{210} \mathrm{~Pb}$. The EF for ${ }^{210} \mathrm{~Pb}$ are roughly similar to those for stable $\mathrm{Pb}$, but, in zooplankton and in the hepatopancreas, are substantially less than those for ${ }^{210} \mathrm{Po}$. Much of the ${ }^{210} \mathrm{~Pb}$ data in the literature are from samples for which ${ }^{210}$ Po values are also reported, and the fact that ${ }^{210} \mathrm{~Pb}$ is not enriched in the marine hepatopancreas to anything like the same extent as ${ }^{210} \mathrm{Po}$ is well-established (Heyraud and Cherry, 1979). A graduation in the properties of the elements in this group is suggested: ${ }^{210} \mathrm{~Pb}$ and $\mathrm{Pb}$ are at the lower end of the marine biological activity scale, whereas ${ }^{210} \mathrm{Po}$ is with $\mathrm{Ag}, \mathrm{Cd}$ and $\mathrm{Se}$ at the upper end. The dashed line between $\mathrm{Hg}$ and $\mathrm{Cu}$ indicates a possible sub-classification; 5 of the 6 elements or isotopes above this line have EF in zooplankton which are comparable with or greater than EF in the hepatopancreas, whereas the 5 below the line all have EF in the hepatopancreas at least an order of magnitude greater than $\mathrm{EF}$ in zooplankton.

It is tempting to proceed beyond this proposed subclassification and to start to compare the EF between neighbouring elements, but the level of accuracy of the figures is such that this is probably not warranted in any detail. Thus, although it is satisfying to note that the $\mathrm{EF}$ for ${ }^{210} \mathrm{~Pb}$ and stable $\mathrm{Pb}$ are within a factor of 5 of each other in all 4 domains for which data are available, it would be unwise to speculate on the significance or otherwise of the inversion which is to be noted in the $\mathrm{EF}$ for ${ }^{210} \mathrm{~Pb}$ and $\mathrm{Pb}$ between zooplankton and zooplankton faecal pellets. The EF for $\mathrm{Pb}$ in faecal 
pellets is based on a single determination in a single sample, and cannot be guaranteed; moreover, most of the $\mathrm{Pb}$ and ${ }^{210} \mathrm{~Pb}$ data in zooplankton have not been obtained from the same samples.

\section{THE ENRICHMENT OF ${ }^{210}$ Po}

Regarding the behaviour of ${ }^{210}$ Po in the hepatopancreas, the main conclusion to be drawn from Table 2 is, however, clear: if light is to be thrown on the mechanism of ${ }^{210} \mathrm{Po}$ incorporation and distribution in the hepatopancreas by studying elements whose behaviour is likely to be similar, then it is with elements such as $\mathrm{Ag}, \mathrm{Cd}$ and Se that one should start. Further, the tabulation can be used predictively to obtain a rough idea of how other elements might be expected to behave in cases where no data are available. Consider, for example, elements such as Au and I: data for these 2 elements are available in the references cited for some of the sample categories listed but not for the hepatopancreas, and we mention that in all cases the indication is that these 2 elements will also be placed in the bottom group. High EF values are accordingly to be expected for them in the marine hepatopancreas. Another element for which no hepatopancreas data are available is sulphur. Along with Se and Te, $\mathrm{S}$ is in the same column of the periodic table as ${ }^{210} \mathrm{Po}$; it is moreover an element which plays a vital role in biological processes, and a similarity between ${ }^{210} \mathrm{Po}$ and $\mathrm{S}$ behaviour patterns must be considered an a priori possibility. The $\mathrm{S}$ content of zooplankton appears to be about $9000 \mu \mathrm{g} \mathrm{g}^{-1}$ (Goldhaber and Kaplan, 1974), which implies an EF for $S$ in zooplankton of about $3 \times 10^{4}$. This would place $S$ close to the bottom of Column 4 of Table 2, along with $\mathrm{Cd}$ and $\mathrm{Se}$; unsurprisingly, $\mathrm{S}$ must be included in the list of elements whose behaviour in the hepatopancreas needs further study if the ${ }^{210} \mathrm{Po}$ problem is to be elucidated.

An association of ${ }^{210}$ Po with proteins containing a high content of sulphydryl groups has been proposed previously (Hill, 1965), and an uptake experiment investigating the binding of ${ }^{210} \mathrm{Po}$ to rat tissues also suggested that the sulphydryl group of cysteine might be an important binding site (Lanzola et al., 1973). Ponikarova and Popov (1978) reported the incorporation of ${ }^{210} \mathrm{Po}$ and its chemical analogue ${ }^{127} \mathrm{Te}$ into the cystine molecular structure in a laboratory experiment with plants. Continuing in this vein, it is worth noting that the elements $\mathrm{Ag}, \mathrm{Cd}, \mathrm{Cu}, \mathrm{Hg}$ and $\mathrm{Zn}$ from the fourth group have one further property in common: they are all known to be associated with metallothioneins. Metallothioneins are a group of low molecular weight $\left(\sim 10^{4}\right)$ cytoplasmic metalloproteins with high affinity for the 5 elements listed (Cherian and Goyer, 1978); they have certain common characteristic properties, notably a high cysteine content of about $30 \%$. Although the above evidence is fragmentary, it is nonetheless suggestive: an association of ${ }^{210} \mathrm{Po}$ with sulphur-containing amino acids should be borme in mind in future investigations of the behaviour of ${ }^{210} \mathrm{Po}$ in the hepatopancreas.

\section{COMPARISON WITH ENRICHMENT FACTORS IN A NON-MARINE DOMAIN}

In conclusion it is interesting to compare the hepatopancreas enrichment factors with those in a non-marine domain in which similarly high factors are found, viz. the particulate matter collected by air filtration in plumes and vents at Mount Etna, Sicily in June 1976 (Buat-Menard and Arnold, 1978; Lambert et al., 1979). This comparison is made in Table 5 for all elements for which both hepatopancreas and volcanic emission data are available plus the elements $\mathrm{Sc}, \mathrm{Au}$, $\mathrm{Br}$ and $\mathrm{S}$. Two sets of data are available for the volcanic emission material, viz. main plume samples and hot vent samples. The similarity of the enrichment factors with those for the hepatopancreas samples is striking, particularly in view of the fact that volcanic events and

Table 5. Enrichment factors (EF) in the hepatopancreas and in volcanic emission particulates. EF for hepatopancreas from Table 2; EF for volcanic emissions from Buat-Menard and Arnold (1978) and Lambert et al. (1979)

\begin{tabular}{|c|c|c|c|}
\hline & $\begin{array}{l}\text { Hepato- } \\
\text { pancreas }\end{array}$ & $\begin{array}{l}\text { Main plume } \\
\text { emissions }\end{array}$ & $\begin{array}{l}\text { Hot vent } \\
\text { emissions }\end{array}$ \\
\hline $\mathrm{Sc}$ & - & $3 \times 10^{-1}$ & $2 \times 10^{0}$ \\
\hline $\mathrm{Fe}$ & $6 \times 10^{0}$ & $7 \times 10^{-1}$ & $1 \times 10^{0}$ \\
\hline $\mathrm{Mn}$ & $2 \times 10^{1}$ & $6 \times 10^{0}$ & $3 \times 10^{2}$ \\
\hline $\mathrm{Ni}$ & $3 \times 10^{1}$ & $2 \times 10^{1}$ & $2 \times 10^{3}$ \\
\hline $\mathrm{Co}$ & $7 \times 10^{1}$ & $4 \times 10^{0}$ & $2 \times 10^{2}$ \\
\hline $\mathrm{Cr}$ & $7 \times 10^{1}$ & $3 \times 10^{0}$ & $5 \times 10^{1}$ \\
\hline $\mathrm{Ca}$ & $2 \times 10^{1}$ & $7 \times 10^{0}$ & $2 \times 10^{1}$ \\
\hline $\mathrm{K}$ & $2 \times 10^{2}$ & $9 \times 10^{0}$ & $6 \times 10^{3}$ \\
\hline $\mathrm{Na}$ & $1 \times 10^{3}$ & $2 \times 10^{1}$ & $3 \times 10^{3}$ \\
\hline $\mathrm{Pb}$ & $3 \times 10^{2}$ & $4 \times 10^{2}$ & $1 \times 10^{5}$ \\
\hline${ }^{210} \mathrm{~Pb}$ & $4 \times 10^{2}$ & $9 \times 10^{3}$ & - \\
\hline $\mathrm{Sb}$ & $2 \times 10^{3}$ & $7 \times 10^{2}$ & $4 \times 10^{3}$ \\
\hline $\mathrm{Zn}$ & $3 \times 10^{3}$ & $6 \times 10^{2}$ & $2 \times 10^{4}$ \\
\hline $\mathrm{Hg}$ & $3 \times 10^{3}$ & $1 \times 10^{4}$ & $1 \times 10^{5}$ \\
\hline $\mathrm{Cu}$ & $4 \times 10^{3}$ & $2 \times 10^{2}$ & $9 \times 10^{4}$ \\
\hline${ }^{210} \mathrm{Po}$ & $4 \times 10^{4}$ & $1 \times 10^{5}$ & - \\
\hline As & $5 \times 10^{4}$ & $8 \times 10^{2}$ & $1 \times 10^{4}$ \\
\hline $\mathrm{Ag}$ & $1 \times 10^{5}$ & $2 \times 10^{3}$ & $3 \times 10^{6}$ \\
\hline $\mathrm{Cd}$ & $2 \times 10^{5}$ & $2 \times 10^{3}$ & $3 \times 10^{6}$ \\
\hline $\mathrm{Se}$ & $2 \times 10^{5}$ & $2 \times 10^{5}$ & $2 \times 10^{6}$ \\
\hline $\mathrm{Aul}$ & - & $9 \times 10^{3}$ & $3 \times 10^{5}$ \\
\hline $\mathrm{S}$ & - & $2 \times 10^{4}$ & $2 \times 10^{5}$ \\
\hline $\mathrm{Br}$ & - & $4 \times 10^{4}$ & $2 \times 10^{6}$ \\
\hline
\end{tabular}


marine biological processes operate at completely different temperatures. Despite this temperature difference, it may not be too fanciful to describe the hepatopancreas as a marine biological domain which is thermodynamically analogous to the geological domain of volcanic activity; the former is a major site of metabolic activity in the biological ecosystem. whereas the latter is a major site of energy release in geological terms. Perhaps the ultimate explanation of the behaviour of ${ }^{210} \mathrm{Po}$ (and other 'biological' trace elements) in the hepatopancreas lies in bioenergetics and thermodynamics.

Acknowledgements. The International Laboratory of Marine Radioactivity operates under a tripartite agreement between the International Atomic Energy Agency, the Government of the Principality of Monaco and the Oceanographic Institute at Monaco. The present work was also supported by the Marine Pollution Programme of the South African Co-operative Scientific Programmes Unit. We are grateful to $\mathrm{V} T$. Bowen, R. Chesselet, S. W. Fowler, R. Fukai, J. C. Guary, G. Lambert, J. D. Smith and A. Walton for critical comments.

\section{LITERATURE CITED}

Beasley, T. M., Heyraud, M., Higgo, J. J. W., Cherry, R. D., Fowler, S. W. (1978). ${ }^{210} \mathrm{Po}$ and ${ }^{210} \mathrm{~Pb}$ in zooplankton fecal pellets. Mar. Biol. 44: 325-328

Bennett, J. T., Carpenter, R. (1979). Concentrations and temporal variations of ${ }^{210} \mathrm{Po},{ }^{210} \mathrm{~Pb}$, and $\mathrm{Al}$ in the surf zone ecosystem of Copalis Beach, Washington. Estuar. coast. mar. Sci. 8: 127-140

Bertine, K. K., Goldberg, E. D. (1971). Fossil fuel combustion and the major sedimentary cycle. Science, N. Y. 173: 233-235

Brewer, P. G. (1975). Minor elements in sea water. In: Riley, J. P., Skirrow, G. (ed.) Chemical oceanography, Vol. 1 Chap. 7. Academic Press, London, p. 415-496

Brewer, P. G., Nozaki, Y., Spencer, D. W., Fleer, A. P. (1980). Sediment trap experiments in the deep North Atlantic: isotopic and elemental fluxes. J. mar. Res. 38: 703-728

Buat-Menard, P., Amold, M. (1978). The heavy metal chemistry of atmospheric particulate matter emitted by Mount Etna Volcano. Geophys. Res. Lett. 5: 245-248

Buat-Menard, P., Chesselet, R. (1979). Variable influence of the atmospheric flux on the trace metal chemistry of oceanic suspended matter. Earth Planet. Sci. Lett. 42: 399-411

Cherian, M. G., Goyer, R. A. (1978). Minireview. Metallothioneins and their role in the metabolism and toxicity of metals. Life Sciences 23: 1-10

Cherry, R. D., Shannon, L. V. (1974). The alpha radioactivity of marine organisms. Atom. Energy Rev. 12: 3-45

Cherry, R. D., Fowler, S. W., Beasley, T. M., Heyraud, M. (1975). Polonium-210: its vertical oceanic transport by zooplankton metabolic activity. Mar. Chem. 3: 105-110

Cherry, R. D., Heyraud, M. (1981). Polonium-210 content of marine shrimp: variation with biological and environmental factors. Mar. Biol. 65: 165-175

Cherry, R. D., Heyraud, M. (1982). Evidence of high natural radiation doses in certain mid-water oceanic organisms. Science, N. Y. 218: 54-56

Duce, R. A., Hoffman, G. L., Zoller, W. M. (1975). Atmospheric trace metals at remote northern and southern hemisphere sites: pollution or natural? Science, N. Y, 187: 59-61

Eisler, R. (1973). Annotated bibliography on biological effects of metals in aquatic environments (Nos. 1-567). U.S. Environmental Protection Agency EPA-R3-73-007

Eisler, R., Wapner, M. (1975). Second annotated bibliography on biological effects of metals in aquatic environments (No. 568-1292). U. S. Environmental Protection Agency EPA-600/3-75-008

Eisler, R., O'Neil, D. J., Thompson, G. W. (1978). Third annotated bibliography on biological effects of metals in aquatic environments (No. 1293-2246). U.S. Environmental Protection Agency EPA-600/3-78-005

Eisler, R., Rossoll, R. M., Gaboury, G. A. (1979). Fourth annotated bibliography on biological effects of metals in aquatic environments (No. 2247-3142). U. S. Environmental Protection Agency EPA-600/3-79-084

Eisler, R. (1981). Trace metal concentrations in marine organisms. Pergamon Press, London

Folsom, T. R., Wong, K. M., Hodge, V. F. (1972). Some extreme accumulations of natural polonium radioactivity observed in certain oceanic organisms. In: Adams, J. A. S., Lowder, W. M., Gesell, T. F. (ed.) The natural radiation environment, II. Rice University and the University of Texas, Houston, NTIS, p. 863-882

Fowler, S. W. (1977). Trace elements in zooplankton particulate products. Nature, Lond 269: 51-53

Fukai, R., Ballestra, S., Holm, E. (1976). ${ }^{241}$ Americium in Mediterranean surface waters. Nature, Lond. 264: 739-740

Goldhaber, M. B., Kaplan, I. (1974). The sulfur cycle. In: Goldberg, E. D. (ed.) The sea, Vol. 5, Chap. 17. Wiley, New York, p. 569-655

Guary, J. C., Higgo, J. J. W., Cherry, R. D., Heyraud, M. (1981). High concentrations of transuranics and natural radioactive elements in the branchial hearts of the cephalopod Octopus vulgaris. Mar. Ecol. Prog. Ser. 4: 123-126

Heyraud, M., Cherry, R. D. (1979). Polonium-210 and lead210 in marine food chains. Mar. Biol. 52: 227-236

Heyraud, M. (1982). Contribution à l'étude du polonium-210 et du plomb-210 dans les organismes marins et leur environment. Thèse de Doctorat d'Etat, Univ. Paris

Heyraud, M. Cherry, R. D. (1983). The correlation of ${ }^{210}$ Po and ${ }^{210} \mathrm{~Pb}$ enrichments in the sea-surface microlayer with neuston biomass. Contin. Shelf Res. 1: 283-293

Higgo, J. J. W., Cherry, R. D., Heyraud, M., Fowler, S. W (1977). Rapid removal of plutonium from the oceanic surface layer by zooplankton faecal pellets. Nature, Lond. 266: $623-624$

Higgo, J. J. W., Cherry, R. D., Heyraud, M., Fowler, S. W., Beasley, T. M. (1980). The vertical oceanic transport of alpha-radioactive nuclides by zooplankton fecal pellets. In: Gesell, T. F., Lowder, W. M. (ed.) The natural radiation environment III, Vol. 1. U.S. Department of Energy, CONF-780422, p. 502-513

Hill, C. R. (1965). Polonium-210 in man. Nature, Lond. 208: $423-428$

Hodge, V., Johnson, S. R., Goldberg, E. D. (1978). Influence of atmospherically transported aerosols on surface oceanwater composition. Geochem. J. (Jap.). 12: 7-20

Lambert, G., Buisson, A., Sanak, J., Ardouin, B. (1979). Modification of the atmospheric polonium-210 to lead-210 ratio by volcanic emissions. J. geophys. Res. 84: 6980-6986

Lantzy, R. J., Mackenzie, F. T. (1979), Atmospheric trace metals: global cycles and assessment of man's impact. Geochim. cosmochim. Acta 43: 511-525 
Lanzola, E. E., Allegrini, M. E., Taylor, D. M. (1973). The binding of polonium-210 to rat tissues. Radiat. Res. 56: 370-384

MacKenzie, A. B., Scott, R. D. (1979). Separation of bismuth210 and polonium-210 from aqueous solutions by spontaneous adsorption on copper foils. Analyst, Lond. 104: 1151-1158

Martin, J. H. (1970). The possible transport of trace metals via moulted copepod exoskeletons. Limnol. Oceanogr. 15: $756-761$

Martin, J. H., Knauer, G. (1973). The elemental composition of plankton. Geochim. cosmochim. Acta 37: 1639-1653

Ponikarova, T. M., Popov, D. K. (1978). Incorporation of polonium-210 and its chemical analogues into plant cystine. Radiobiologiya 19: 633-634

Prosser, C. L., Brown, F. A. (1962). Comparative animal physiology (2nd ed.). Saunders, Philadelphia

Spencer, D. W., Brewer, P. G., Fleer, A., Honjo, S., Krishnaswami, S., Nozaki, Y. (1978). Chemical fluxes from a sediment trap experiment in the deep Sargasso Sea. J. mar. Res. 36: 493-523

Taylor, S. R. (1964). Abundance of chemical elements in the continental crust: a new table. Geochim. cosmochim. Acta 28: $1273-1285$

Thein, M., Ballestra, S., Yamato, A., Fukai, R. (1980). Delivery of transuranic elements by rain to the Mediterranean Sea. Geochim. cosmochim. Acta 44: 1091-1098

UNSCEAR (1977). Sources and effects of ionizing radiation. United Nations Scientific Committee on the Effects of Atomic Radiation. United Nations Publication No. E. 77. IX. 1

Wallace, G. T., Hoffman, G. L., Duce, R. A. (1977). The influence of organic matter and atmospheric deposition on the particulate trace metal concentration of Northwest Atlantic surface seawater. Mar. Chem. 5: 143-170

Whitfield, M. (1979). The mean oceanic residence time (MORT) concept - a rationalization. Mar. Chem. 8: 101-123

Wood, J. M. (1974). Biological cycles for toxic elements in the environment. Science, N. Y. 183: 1049-1052

Zoller, W. H., Gladney, E. S., Duce, R. A. (1974). Atmospheric concentrations and sources of trace metals at the South Pole. Science, N. Y. 183: 198-200

This paper was presented by Professor J. G. Field; it was accepted for printing on May 2, 1983 